\title{
Sensitivity analysis of mesoscale simulations to physics parameterizations: a case study of storm Ciara over the Belgian North Sea using WRF-ARW
}

\author{
Adithya Vemuri ${ }^{1}$, Sophia Buckingham ${ }^{1}$, Wim Munters ${ }^{1}$, Jan Helsen ${ }^{2}$, and Jeroen van Beeck ${ }^{1}$ \\ ${ }^{1}$ Department of Environmental and Applied Fluid Dynamics, von Karman Institute for Fluid Dynamics, Waterloosesteenweg \\ 72, 1640 Sint-Genesius-Rode, Belgium \\ ${ }^{2}$ Department of Mechanical Engineering, Vrije Universiteit Brussel, Boulevard de la Plaine 2, 1050 Ixelles, Belgium \\ Correspondence: Adithya Vemuri (adithya.vemuri@vki.ac.be)
}

\begin{abstract}
.
The Weather, Research and Forecasting (WRF) model includes a multitude of physics parameterizations to account for atmospheric dynamics and interactions such as turbulent fluxes within the planetary boundary layer (PBL), long and short wave radiation, hydrometeor representation in microphysics, cloud ensemble representation in cumulus, amongst others. A sensitivity analysis is conducted in order to identify the optimal WRF-physics set-up and impact of temporal resolution of re-analysis dataset for the event of sudden changes in wind direction that can become challenging for reliable wind energy operations. In this context, Storm Ciara has been selected as a case study to investigate the influence of a broad combination of different interacting physics-schemes on quantities of interest that are relevant for energy yield assessment. Of particular relevance to fast transient weather events, two different temporal resolutions (1-hourly and 3-hourly) of the lateral boundary condition's re-analysis dataset, ERA5, are considered. Physics parameterizations considered in this study include: two PBL schemes (MYNN2.5 and scale-aware Shin Hong PBL), four cumulus schemes (Kain-Fritsch, Grell-Devenyi, and scale-aware Grell-Freitas and multi-scale Kain-Fritsch,) and three microphysics schemes (WSM5, Thompson and Morrison) coupled with two geospatial configurations for WRF simulation domains. The resulting WRF predictions are assessed by comparison to observational RADAR reflectivity data on precipitation. In addition, SCADA data on wind direction and wind speed from an offshore wind farm located in the Belgian North Sea is considered to assess modeling capabilities for local wind behavior at farm level. For precipitation, results are shown to be very sensitive to model setup, but no clear trends can be observed. For wind-related variables on the other hand, results show a definite improvement in accuracy when both scale-aware cumulus and PBL parameterizations are used in combination with 1-hourly temporal resolution reanalysis data and extended domain sizes.
\end{abstract}

\section{Introduction}

Extreme weather phenomena such as low-level jets, sudden changes in wind direction, extreme wind shear (Kalverla et al., 2017; Aird et al., 2021), wind ramps (Gallego-Castillo et al., 2015) and storms (Solari, 2020) are capable of causing severe dynamic loading on wind turbine components (Negro et al., 2014; AbuGazia et al., 2020; Chi et al., 2020). Furthermore, pre- 
cipitation associated to these phenomena can lead to early blade degradation through leading-edge erosion (Law and Koutsos, 2020). As such, these extreme weather events (EWE) play a significant role in the wind turbine's operational lifetime and must be considered at design stage to ensure that ultimate loads are not exceeded and fatigue requirements are met. Furthermore, such events may cause sudden changes in power production leading to grid imbalance and economic losses. Accurate modeling and forecasting of such EWE is hence crucial to tackle these challenges in view of current and future expansion of both onshore and offshore wind energy. Numerical weather prediction (NWP) models provide a promising approach to help identify problematic weather events and to predict their occurrence through operational forecasting (Bauer et al., 2015). Among different available NWP codes, the open-source Weather, Research and Forecasting model developed by NCAR/NOAA (Skamarock et al., 2008) is commonly used for its ability to represent the various interacting processes and dynamics of the atmosphere such as the distribution of fluxes within the planetary boundary layer (PBL), the determination of cloud ensembles and compensating subsidence for convective/cumulus systems, the accurate representation of evolving hydrometeor species, solar irradiation, land-surface interactions and heat and moisture fluxes in the surface layer (SL). An expanse of physics parameterizations and options are available in WRF to represent the infuence of these phenomena on local weather systems. However, predictions are found to be highly sensitive on the selection of these sub-grid scale models, the location and the type of weather event, the lateral boundary conditions used to drive the flow, and the simulation domain configuration.

Sensitivity analyses are typically conducted to identify the optimal combination of physics-schemes in the event of a specific type of weather system over a given area (see, e.g. Efstathiou et al. 2013; Santos-Alamillos et al. 2013; Kala et al. 2015). To date, this type of investigation has not been performed over the Belgian North Sea, nor has any previous study to the authors' best knowledge looked at how the extreme weather event is experienced from a wind-farm perspective through comparison with operational SCADA data. This work aims to tackle this challenge by considering a wide range of interacting physical parameterizations, more specifically on cumulus, microphysics and PBL schemes. Furthermore, we assess the need for high temporal resolution mesoscale forcing data and extended numerical domains for the prediction of wind and precipitation quantities of interest for wind farm design and operation.

The cumulus, microphysics and PBL parameterizations defined in WRF follow a multitude of large-scale and sub-grid scale modeling techniques, primarily divided into scale-aware and non-scale aware parameterizations. The scale-aware schemes promise to better reproduce convective and turbulent mixing effects in the so-called gray zone, i.e. for high-resolution simulation grids which are on the verge of allowing explicitly resolution of these effects rather than fully parameterizing them (Wyngaard, 2004; Hong and Dudhia, 2012). The cumulus parameterizations represent the ensemble effects of convective clouds as a function of larger-scale processes and conditions by formulating the statistical effects of moist convection and convective rainfall within a grid-column. These are further divided into mass-flux type and adjustment type schemes. The mass-flux type schemes convert convective available potential energy from a single grid column defined in WRF into compensating subsidence. For example, the Kain-Fritsch (KF) scheme (Kain, 2004) is a commonly-used one-dimensional mass-flux cumulus scheme that considers deep and shallow convection and includes hydrometeor detrainments from clouds, rain, ice, and snow. The scheme is designed to run at horizontal resolutions coarser than $25 \mathrm{~km}$. The multi-scale Kain-Fritsch (msKF) cumulus parameterization (Zheng et al., 2016) updates the original KF parameterization by introducing scale-aware parameterized cloud 
dynamics based on a dynamic length scale in order to improve the prediction accuracy at higher horizontal resolutions below $10 \mathrm{~km}$. The Grell-Dévényi 3D ensemble (GD-3D) cumulus parameterization (Grell and Dévényi, 2002) relies on combining ensemble and data assimilation techniques to represent the local convection and provides more tunable parameters for further calibration of the model. The Grell-Frietas (GF) cumulus parameterization (Grell and Freitas, 2014) is an adjustment type parameterization that explores; redistribution of compensating subsidence derived from GD-3D to neighbouring grid cells using distribution functions and adapts the scale-aware parameterization from Arakawa et al. (2011). The GF cumulus parameterization was designed and tested for a horizontal resolution of $5 \mathrm{~km}$. The study by Jeworrek et al. (2019) highlights how crucial the choice in cumulus parameterization is for obtaining accurate WRF predictions of precipitation patterns, in particular when going from parameterized to resolved convective scales. In this work, the KF, msKF, GD-3D and GF schemes are considered in order to evaluate the performance of WRF across the convective gray-zone transition.

The microphysical parameterization is an emulation of processes for moisture removal from the atmosphere via modeling hydrometeor distributions based on thermodynamic and kinematic fields defined in the model. The schemes determine the spatial distribution of precipitation and vertical distribution of hydrometeor mass and latent heat. Most commonly used microphysical schemes are the so-called bulk schemes, in which a mathematical distribution for hydrometeor number concentration versus particle size is defined using negative exponential or gamma distributions. Microphysical parameterizations are further divided by their complexity and tunable parameters such as considered moments of distributions (single, double, etc), and intercepts or slope parameters for the distributions. The microphysics schemes considered in this sensitivity analysis are the WSM5 single-moment 5-class (i.e. with 5 hydrometeor species) microphysics parameterization (Hong et al., 2004), the Thompson single-moment (except ice) 6-class scheme (Thompson et al., 2008) and the Morrison double-moment 6-class scheme (Morrison et al., 2009). In this respect, Hong and Lim (2006) illustrated the advantages in including a greater number of hydrometeor species for microphysical representations and a better prediction of precipitation levels. Similar results were observed by Jeworrek et al. (2019), calling for microphysics parameterizations with greater fidelity in hydrometeor representation, such as the Morrison and Thompson schemes, and scale-aware cumulus parameterizations, such as multi-scale KF and GF schemes, in order to more accurately reproduce precipitation.

Concerning the parameterization of boundary-layer turbulence, mesoscale NWP models employ PBL schemes that rely on the horizontal homogeneity assumption to redistribute surface fluxes vertically within the atmospheric boundary layer. However, for grid spacings that are fine enough $(\approx 1 \mathrm{~km})$, three-dimensional atmospheric turbulence becomes partially resolved, which violates the basic assumption employed by classical one-dimensional PBL schemes. The gray-zone modeling challenge for PBL turbulence has led to the development of scale-aware PBL schemes which, as opposed to non-scale-aware formulations, partially resolving turbulent mixing at gray-zone resolutions depending on grid size. This work considers two PBL parameterizations: a non-scale-aware Mellor-Yamada-Nakanishi-Niino (MYNN) scheme (Nakanishi and Niino, 2006) and a scale-aware Shin-Hong scheme (Shin and Hong, 2015). The MYNN PBL scheme is a one-dimensional turbulence kinetic energy prediction scheme that solves for a vertical eddy viscosity profile in a grid column considering, among others, buoyancy and shear production, boundary-layer stability and vertical mixing. On the other hand, Shin-Hong is a scale-aware one-dimensional diagnostic non-local PBL scheme representing non-local transport by large eddies in the boundary layer. The 
Shin-Hong scheme modifies the YSU PBL scheme (Hong et al., 2006) for sub-kilometer transition scales (1 km down to 200 $\mathrm{m}$ ) by reducing the strength of the non-local term with decreasing grid size, assuming gradual resolution of the largest eddies. While it has been found to outperform conventional PBL formulations for desert convective boundary layers (Xu et al., 2018) and for the XPIA study in the western Great Plains of the United States (Doubrawa and Muñoz-Esparza, 2020), its interaction with cumulus and microphysics options is yet to be tested for extreme weather in coastal environments featuring strong interaction between PBL and microphysical processes.

In the context of wind energy applications, various sensitivity studies have been conducted with the aim of determining a universal "best" case WRF setup to assess local wind resources (Hahmann et al., 2015; Giannakopoulou and Nhili, 2014; Carvalho et al., 2012). The literature presents equivocal results from a multitude of sensitivity analyses conducted at various locations around the planet, indicating a high dependency on the physics combinations and lateral boundary conditions used. Concerning the estimation of wind energy production compared to measured wind data, Hahmann et al. (2015) study the long-term sensitivity of simulated WRF offshore climatology evaluated against wind LiDAR observations indicating a strong sensitivity to PBL parameterizations and the spin-up period, and insensitivity to global reanalysis and vertical resolution of the model. Carvalho et al. (2014), for offshore and onshore areas in the Iberian Peninsula, indicated a close dependency of PBL and SL parameterizations with different physics combinations, favoring better reproduction of different prognostic variables. Cunden et al. (2018) performed a sensitivity analysis considering different combinations of non-scale-aware cumulus, PBL and microphysics schemes (despite kilometer-range resolutions) for the Island of Mauritius under clear and extreme weather (cyclonic and anti-cyclonic), and were able to identify a best case WRF setup. In contrast, a similar study by Islam et al. (2015) for the Haiyan tropical cyclone over west Pacific Ocean concluded in no particular combination of WRF physics to best reproduce the extreme weather event. For the European continent, studies by García-Díez et al. (2013); Stergiou et al. (2017); Mooney et al. (2013) have conducted year-long and/or long-term sensitivity analyzes indicating a wide spread of possible physics parameterizations depending on the type of local weather event, season and time-lapse considered within the diurnal cycle.

As discussed above, the optimal selection of WRF physics parameterizations remains an important open challenge for accurate wind and weather modeling. The current study quantifies the sensitivity of WRF simulation results to physical parameterizations and numerical setup, and aims at identifying most suitable combinations for modeling the storm Ciara EWE passing over the Belgian offshore wind farms in the North Sea in February 2020. A simplified multi-variant sensitivity analysis considering 12 combinations of PBL, cumulus, microphysics, temporal resolution of lateral boundary conditions and geospatial nested domain configurations are investigated. The remainder of this paper is structured as follows. Firstly, the storm Ciara extreme weather event is introduced in Section 2. Next, the numerical methodology and setup are introduced in Section 3, where also the design of the sensitivity matrix is further described. Subsequently, the results are presented and discussed in Section 4. Lastly, conclusions and perspective are exposed in Section 5. 


\section{Description of the storm Ciara event}

The case study selected in this study is one of the first extratropical cyclones to hit the European continent in the year 2020, storm Ciara. Originating on the Atlantic Ocean, the storm occurred on 10 February 2020 over the Belgian North Sea, transpiring from North America (starting 3 February 2020) to the European continent (16 February 2020). Storm Ciara swept across the majority of western Europe including United Kingdom and Norway, bringing in heavy precipitation and strong winds with a maximum recorded wind gust of $219 \mathrm{~km} \mathrm{~h}^{-1}$ at Cap Corse, Corsica, France. Over Belgium, the Royal Meteorological Institute - Belgium (RMI-B) reported wind gusts of up to $115 \mathrm{~km} \mathrm{~h}^{-1}$ in Ostend, located at the Belgian offshore coast, with precipitation averaging $28 \mathrm{~mm}$ in few hours accompanied by strong winds and thunderstorms over the local region.

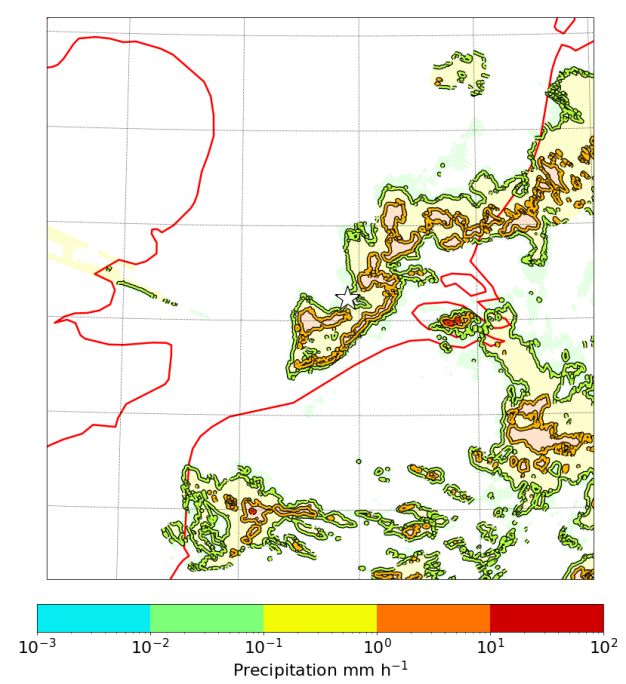

Figure 1. Observed RADAR reflectivity on 10 February 2020 at 04:00 provided by a C-band Doppler RADAR located near the Belgian offshore coast in Jabbeke, Belgium.

The selection of this case is motivated by the occurrence of fast changes in wind direction as observed by offshore wind farms located in the Belgian offshore concession zone at several moments during the storm. During the early hours of storm Ciara on 10 February 2020, a commercial offshore wind farm observed fast changes in wind direction of $40^{\circ}$ over few minutes accompanied by concentrated rainfall over a short period of time. This event was investigated with RADAR observations provided by RMI-B, for brevity the time-stamp at 04:40 is presented in Fig. 1, illustrating the presence of a bow-echo transpiring from the British isles to Belgium, indicative of a possible micro-burst phenomena (Fujita, 1978). Fast changes in wind direction are potentially influential of the state of power and grid balances and have been found to be potentially harmful for operational conditions and lifetime of wind turbines as demonstrated in the studies by Damiani et al. (2018); Bakhshi and Sandborn (2016). With the addition to RADAR data and the availability of operational wind farm data (SCADA), the premise of this study provides a unique opportunity to investigate storm Ciara as felt by the Belgian offshore wind farms and formulate an informed decision on the optimum WRF set-up in the context of wind energy applications. 
Table 1. WRF model setup. Parameters varied in this sensitivity study are shown in italics. Scale-aware physics parametrizations are underlined.

\begin{tabular}{|c|c|}
\hline \multicolumn{2}{|l|}{ Numerical setup } \\
\hline Case studied & storm Ciara, 10 February 2020 \\
\hline Nested domains & 4 \\
\hline Horizontal resolution & $27 \mathrm{~km}(\mathrm{~d} 01) \times 9 \mathrm{~km}(\mathrm{~d} 02) \times 3 \mathrm{~km}(\mathrm{~d} 03) \times 1 \mathrm{~km}(\mathrm{~d} 04)$ \\
\hline Terrain following vertical levels & 57 \\
\hline Model top pressure & $1000 \mathrm{~Pa}$ \\
\hline Time-step & $20 \mathrm{~s}$ \\
\hline Spin-up period & 24 h (9 Feb 2020 00:00 - 10 Feb 2020 00:00) \\
\hline Simulation time & 21 h (10 Feb 2020 00:00 - 10 Feb 2020 21:00) \\
\hline Initial \& boundary conditions & ERA5 reanalysis \\
\hline Domain size & type 1 / type 2 (Fig. 2) \\
\hline Boundary update frequency & $1 h / 3 h$ \\
\hline \multicolumn{2}{|l|}{ Physics parametrizations } \\
\hline Radiation & RRTMG \\
\hline Land surface & unified Noah land-surface \\
\hline$P B L$ & MYNN / Shin-Hong \\
\hline Microphysics & WSM5 / Thompson / Morrison \\
\hline Cumulus & $K F / G D-3 D / \underline{m s K F} / \underline{G F}$ \\
\hline
\end{tabular}

\section{Methodology and Model setup}

This sensitivity study considers the WRF-ARW model version 4.2.2 to study the case of storm Ciara, evaluated against RADAR and SCADA observations from the Belgian North Sea. The model parameters for all WRF simulations are summarized in Table 1. The baseline horizontal resolution in the largest parent domain $\mathrm{d} 01$ is $27 \mathrm{~km}$, while nested domains are sequentially refined with a factor of 3 , resulting in resolutions of 9,3 , and $1 \mathrm{~km}$ for $\mathrm{d} 02$, d03, and d04 respectively. In the vertical direction, 57 terrain following levels are considered with a model top pressure at $1000 \mathrm{~Pa}$. The vertical velocity damping option based on Courant-Friedrichs-Lewy condition as implemented in WRF is also turned on. The model is initialized on 9 February 2020 at 00:00, followed by a spin-up period of 24 hours. Subsequently, the model is run on 10 February 2020 from 00:00 to 21:00, which adequately captures the storm event on the Belgian North Sea. The long-wave and short-wave radiation physics schemes are kept constant as Rapid Radiative Transfer Model (RRTMG) (Iacono et al., 2008). Similarly, the land surface interactions are kept constant as unified Noah land surface model (Mukul Tewari et al., 2004).

In order to sufficiently categorize and distinguish the key features of different parameterizations and options available in WRF, a combination of different simulation pairs in the multi-variant sensitivity Table 2 is considered. A total of 12 WRF simulations are categorized into different simulation pairs $(\mathrm{A}-\mathrm{K})$ assigned to either variations of the temporal resolution of 
Table 2. WRF runs and respective simulation pairs for sensitivity analysis

\begin{tabular}{|c|c|c|c|c|c|c|c|c|c|c|}
\hline$\#$ & $\begin{array}{c}\text { ERA5 } \\
\text { res. }\end{array}$ & $\begin{array}{c}\text { Domain } \\
\text { type }\end{array}$ & $\begin{array}{c}P B L \\
\text { scheme }\end{array}$ & $\begin{array}{c}\text { Microphysics } \\
\text { scheme }\end{array}$ & $\begin{array}{l}\text { Cumulus } \\
\text { scheme }\end{array}$ & $\begin{array}{c}\text { Temporal } \\
\text { pair }\end{array}$ & $\begin{array}{c}\text { Cumulus } \\
\text { pair }\end{array}$ & $\begin{array}{c}\text { Microphysics } \\
\text { pair }\end{array}$ & $\begin{array}{l}\text { PBL } \\
\text { pair }\end{array}$ & $\begin{array}{c}\text { Domain } \\
\text { pair }\end{array}$ \\
\hline 1 & $3 \mathrm{~h}$ & 1 & MYNN & Thompson & $\mathrm{KF}$ & B & & & & \\
\hline 2 & $3 \mathrm{~h}$ & 2 & Shin-Hong & WSM5 & $\mathrm{KF}$ & A & & & & \\
\hline 3 & $1 \mathrm{~h}$ & 2 & MYNN & Thompson & $\mathrm{KF}$ & & & & \multirow{2}{*}{$\begin{array}{c}\text { I } \\
\text { H }\end{array}$} & \multirow{2}{*}{$\mathbf{J}$} \\
\hline 4 & $1 \mathrm{~h}$ & 1 & MYNN & Thompson & $\mathrm{KF}$ & B & & & & \\
\hline 5 & $1 \mathrm{~h}$ & 2 & Shin-Hong & WSM5 & $\mathrm{KF}$ & A & $\mathrm{C}$ & $\mathbf{F}$ & & \\
\hline 6 & $1 \mathrm{~h}$ & 1 & Shin-Hong & Thompson & $\mathrm{KF}$ & & & & H & \multirow{2}{*}{$\mathbf{K}$} \\
\hline 7 & $1 \mathrm{~h}$ & 2 & Shin-Hong & Thompson & $\mathrm{KF}$ & & D & $\mathbf{F}$ & I & \\
\hline 8 & $1 \mathrm{~h}$ & 2 & Shin-Hong & WSM5 & $\mathrm{msKF}$ & & \multirow{5}{*}{$\begin{array}{l}\text { C } \\
\text { D }\end{array}$} & \multirow{3}{*}{$\mathbf{G}$} & & \\
\hline 9 & $1 \mathrm{~h}$ & 2 & Shin-Hong & Thompson & $\mathrm{msKF}$ & & & & & \\
\hline 10 & $1 \mathrm{~h}$ & 2 & Shin-Hong & Morrison & $\mathrm{msKF}$ & & & & & \\
\hline 11 & $1 \mathrm{~h}$ & 2 & Shin-Hong & Morrison & GD-3D & & & & & \\
\hline 12 & $1 \mathrm{~h}$ & 2 & Shin-Hong & Morrison & GF & & & & & \\
\hline
\end{tabular}

lateral boundary conditions, cumulus, microphysics, PBL schemes or geospatial domain configuration. For each variation, at least 2 different simulation pairs have been performed. For example, simulation pairs A and B are assigned to the variation in temporal resolution of the lateral boundary conditions, as within each pair only this temporal resolution is modified. More specifically, the simulation pairs considered are as follows. The sensitivity to 1-hourly versus 3-hourly temporal resolution of lateral ERA5 boundary conditions is assessed with simulation pairs A and B. Further, the sensitivity to scale-aware and non-scale-aware cumulus parameterizations is evaluated through pairs $\mathrm{C}, \mathrm{D}$, and $\mathrm{E}$. The considered cumulus schemes consist of scale-aware GF, msKF, and non-scale-aware KF and GD-3D cumulus schemes. Given the convection-permitting resolutions of d03 and d04, the non-scale-aware KF model is explicitly turned off in these domains in simulation cases $1-7^{1}$. For the scaleaware cumulus models, this explicit deactivation is omitted, as they were specifically designed for operation on the verge of convection-permitting resolutions (Grell and Freitas, 2014; Zheng et al., 2016; Huang et al., 2020). The impact of microphysics schemes WSM5, Thompson and Morrison is illustrated through pairs F and G. Next, the comparison between scale-aware PBL Shin-Hong and non-scale-aware PBL MYNN is shown in pairs $\mathrm{H}$ and I. Finally, pairs $\mathrm{J}$ and K determine sensitivity to the geographical domain size, types 1 and 2 as defined in Fig. 2, where the overall domain sizes are increased in type 2, including an increased northeasterly upstream fetch towards the zone of interest in the Belgian North Sea (central in domain d04).

The simulated wind direction and wind speed from WRF runs are evaluated against front-row averaged SCADA data from the commercial offshore wind farm located in the Belgian North Sea. The precipitation rate using RADAR reflectivity is evaluated against RADAR data from RMI-B. Further, RADAR reflectivity data is qualitatively compared to WRF-simulated reflectivity for 04:40 on 10 February 2020. Model accuracy is assessed using a standard Mean Absolute Error (MAE), as

\footnotetext{
${ }^{1}$ It was verified that this approach results in better reproduction of precipitation cells and lower error metrics as discussed below
} 


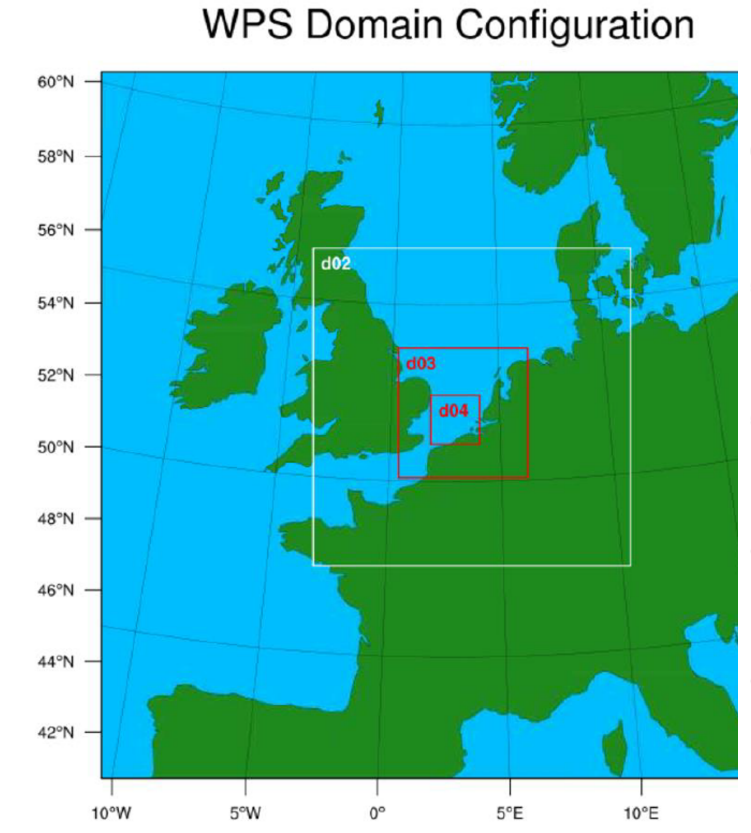

(a) Domain configuration 1

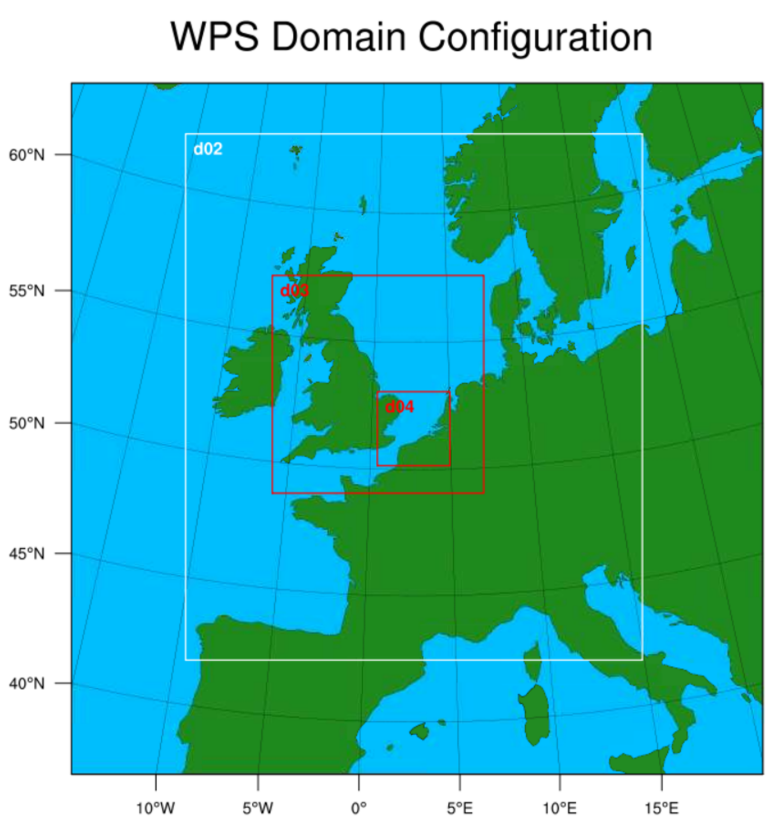

(b) Domain configuration 2

Figure 2. The WRF nested domain configurations considered in this study. (a) Baseline domain configuration, domain - 1 (b) Extended domain configuration 2 , domain - 2 .

well as the Kantorovich distance as described in Wang and Basu (2016). The Kantorovich distance $d$, initially formulated in Kantorovitch (1958), is defined as the solution to the optimal transport problem transforming a discrete source signal $a_{i}(i=$ $1 \ldots m)$ into a target signal $b_{k}(k=1 \ldots n)$,

$d=\min _{x_{i, k}} \sum_{i=1}^{m} \sum_{k=1}^{n} r_{i, k} x_{i, k}$,

where $r_{i, k}$ is a cost associated with the phase shift between indices $i$ and $k$, and $x_{i, k}$ is related to the difference in amplitude between $a_{i}$ and $b_{k}$. In this regard, the Kantorovich distance $d$ is a metric for the similarity between two signals, in this case WRF results and field data, detecting both amplitudes and temporal phase shifts, hence supplementing the standard MAE as a point metric only considering pairwise differences in amplitudes at the same time instance.

To recover a single performance metric, MAE and Kantorovich are normalized to the so-called Nnormalized Euclidean

Distance (NED), given by NED $=\sqrt{\mathrm{MAE}_{N}^{2}+d_{N}^{2}}$, defined as the resultant of normalized mean absolute error $\mathrm{MAE}_{N}$, and normalized Kantorovich distance $d_{N}$ for all simulation runs. Normalization is performed with the mean over all simulations. This study considers a univariate analysis for wind variables and precipitation using performance metrics, NED and Kantorovich distance, respectively. The simulated radar reflectivity is extracted for a single point in space at the location of the offshore wind farm and converted to rainfall rate using the Marshall and Palmer equation (Marshall and Palmer, 1948) and is 
evaluated against reflectivity data from the dual-polarization C-band radar from the RMI-B, located in Jabbeke at the Belgian North Sea coast.

\section{Results and Discussion}

The summary of evaluated metrics for all WRF simulations is presented in Table 3. The table presents MAE, Kantorovich distance and NED for the complete simulation list conducted in this study. The table sequence is organized in the order of increasing computational costs and complexity of physics parameterizations, starting with low resolution of lateral boundary conditions, non-scale-aware physics parameterizations, to scale-aware physics parameterizations with higher resolutions of lateral boundary conditions. Cell colors are assigned to indicate the better metric-specific value in green per column. The average NED is calculated as the average of horizontal wind direction and wind speed NED.

Before discussing the influence of specific parameterizations, we discuss some general trends. Overall, an increasing conformity with observations is observed for simulations with scale-aware physics parameterizations coupled with a larger domain configuration and higher resolution of lateral boundary conditions. The best-case setup in this study is determined to be simulation case 12 with the lowest average NED. Case 12 encompasses scale-aware Shin-Hong PBL scheme coupled with a double moment 6-class Morrison microphysics scheme, a scale-aware GF cumulus scheme and ERA5 $1 \mathrm{~h}$ reanalysis dataset as the lateral boundary conditions. The wind direction and wind speed comparisons for the complete list of WRF simulations along with their ensemble average is presented in Fig. 3. Further, Fig. 4 illustrates individual and ensemble precipitation results as compared to RADAR data. Qualitatively, the simulations capture the changes in wind direction reasonably well when compared to SCADA data. On the other hand, matching wind speeds and precipitation seems significantly more challenging, as shown by the large spread among different modeling setups in the afternoon and evening hours. Interestingly, despite the average NED metric not indicating the ensemble average as a clear winner amongst the simulation cases (due to relatively high errors on wind directions), the precipitation accuracy is greatly improved over the best case 12 .

The remainder of this section focuses on the sensitivity to individual parts of the modeling chain. Firstly, the domain configuration is discussed in Sect. 4.1. Next, the influence of the PBL schemes is shown in Sect. 4.2, followed by the temporal resolution of initial boundary conditions in Sect. 4.3. Subsequently, Sect. 4.4 elaborates on cumulus and microphysics schemes. Finally, Sect. 4.5 provides a synthesis of the observations in this section.

\subsection{Simulation pair: Domain configuration}

The current section investigates the extent to which geographical domain size and upstream fetch affect the generation of finescale wind variations, precipitation cells and convective systems for the current case of storm Ciara. In literature, various studies have provided an equivocal literature on the influence of domain size on WRF simulations ranging from better representation of convective systems in simulations with larger domains and vice versa (see e.g. Bhaskaran et al. 1996; Yu et al. 2021; Wang et al. 2021). Simulation pairs J and K represent four WRF simulations with two different domain configurations (with identical spatial resolution) as presented in Fig. 2. Note that $\mathbf{J}$ furthermore applies a standard MYNN PBL scheme whereas K uses 
Table 3. Evaluation of wind velocity and direction from WRF simulations vs SCADA data averaged over the first row of wind turbines using metrics mean absolute error, Kantorovich distance and mean normalized euclidean distance.

\begin{tabular}{|c|c|c|c|c|c|c|c|c|c|c|c|c|c|}
\hline \multirow[b]{2}{*}{$\#$} & \multirow[b]{2}{*}{$\begin{array}{c}\text { ERA5 } \\
\text { res. }\end{array}$} & \multirow[b]{2}{*}{$\begin{array}{c}\text { Domain } \\
\text { type }\end{array}$} & \multirow[b]{2}{*}{$\begin{array}{c}P B L \\
\text { scheme }\end{array}$} & \multirow[b]{2}{*}{$\begin{array}{c}\text { Microphysics } \\
\text { scheme }\end{array}$} & \multirow[b]{2}{*}{$\begin{array}{c}\text { Cumulus } \\
\text { scheme }\end{array}$} & \multicolumn{3}{|c|}{ Wind direction } & \multicolumn{3}{|c|}{ Wind speed } & \multirow[b]{2}{*}{$\begin{array}{c}\text { Average } \\
\text { NED }\end{array}$} & \multirow{2}{*}{$\begin{array}{l}\text { Precipitation } \\
\text { Kantorovich }\end{array}$} \\
\hline & & & & & & MAE & Kantorovich & NED & MAE & Kantorovich & NED & & \\
\hline 1 & $3 \mathrm{~h}$ & 1 & MYNN & Thompson & $\mathrm{KF}$ & 8.79 & $1.06 \mathrm{E}+04$ & 1.67 & 2.96 & $4.11 \mathrm{E}+03$ & 1.93 & 1.80 & $7.42 \mathrm{E}+02$ \\
\hline 2 & $3 \mathrm{~h}$ & 2 & Shin-Hong & WSM5 & $\mathrm{KF}$ & 7.84 & $1.28 \mathrm{E}+04$ & 1.75 & 2.13 & $3.19 \mathrm{E}+03$ & 1.44 & 1.60 & $6.96 \mathrm{E}+02$ \\
\hline 3 & $1 \mathrm{~h}$ & 2 & MYNN & Thompson & $\mathrm{KF}$ & 9.83 & $4.68 \mathrm{E}+03$ & 1.49 & 2.85 & $5.93 \mathrm{E}+03$ & 2.35 & 1.92 & $4.16 \mathrm{E}+02$ \\
\hline 4 & $1 \mathrm{~h}$ & 1 & MYNN & Thompson & $\mathrm{KF}$ & 7.61 & $1.05 \mathrm{E}+04$ & 1.55 & 2.72 & $3.47 \mathrm{E}+03$ & 1.70 & 1.63 & $6.57 \mathrm{E}+02$ \\
\hline 5 & $1 \mathrm{~h}$ & 2 & Shin-Hong & WSM5 & $\mathrm{KF}$ & 7.50 & $1.24 \mathrm{E}+04$ & 1.69 & 1.76 & $2.57 \mathrm{E}+03$ & 1.17 & 1.43 & $2.97 \mathrm{E}+02$ \\
\hline 6 & $1 \mathrm{~h}$ & 1 & Shin-Hong & Thompson & $\mathrm{KF}$ & 5.49 & $1.12 \mathrm{E}+04$ & 1.41 & 2.06 & $3.56 \mathrm{E}+03$ & 1.51 & 1.46 & $5.32 \mathrm{E}+02$ \\
\hline 7 & $1 \mathrm{~h}$ & 2 & Shin-Hong & Thompson & $\mathrm{KF}$ & 6.94 & $1.11 \mathrm{E}+04$ & 1.53 & 2.13 & $3.45 \mathrm{E}+03$ & 1.50 & 1.51 & $3.06 \mathrm{E}+02$ \\
\hline 8 & $1 \mathrm{~h}$ & 2 & Shin-Hong & WSM5 & $\mathrm{msKF}$ & 6.12 & $1.10 \mathrm{E}+04$ & 1.45 & 1.68 & $1.37 \mathrm{E}+03$ & 0.90 & 1.17 & $6.32 \mathrm{E}+02$ \\
\hline 9 & $1 \mathrm{~h}$ & 2 & Shin-Hong & Thompson & $\mathrm{msKF}$ & 6.85 & 7.37E+03 & 1.25 & 1.74 & $1.67 \mathrm{E}+03$ & 0.98 & 1.112 & $6.01 \mathrm{E}+02$ \\
\hline 10 & $1 \mathrm{~h}$ & 2 & Shin-Hong & Morrison & $\mathrm{msKF}$ & 6.06 & $7.37 \mathrm{E}+03$ & 1.16 & 1.87 & $1.74 \mathrm{E}+03$ & 1.04 & 1.10 & $9.61 \mathrm{E}+02$ \\
\hline 11 & $1 \mathrm{~h}$ & 2 & Shin-Hong & Morrison & GD-3D & 5.24 & $9.71 \mathrm{E}+03$ & 1.26 & 2.07 & $2.97 \mathrm{E}+03$ & 1.37 & 1.32 & $4.99 \mathrm{E}+02$ \\
\hline 12 & $1 \mathrm{~h}$ & 2 & Shin-Hong & Morrison & GF & 5.87 & $5.65 \mathrm{E}+03$ & 1.03 & 1.80 & $2.61 \mathrm{E}+03$ & 1.20 & 1.111 & $6.50 \mathrm{E}+02$ \\
\hline 13 & & & Ensem & & & 5.72 & $8.74 \mathrm{E}+03$ & 1.24 & 1.55 & $2.38 \mathrm{E}+03$ & 1.08 & 1.16 & $3.02 \mathrm{E}+02$ \\
\hline
\end{tabular}

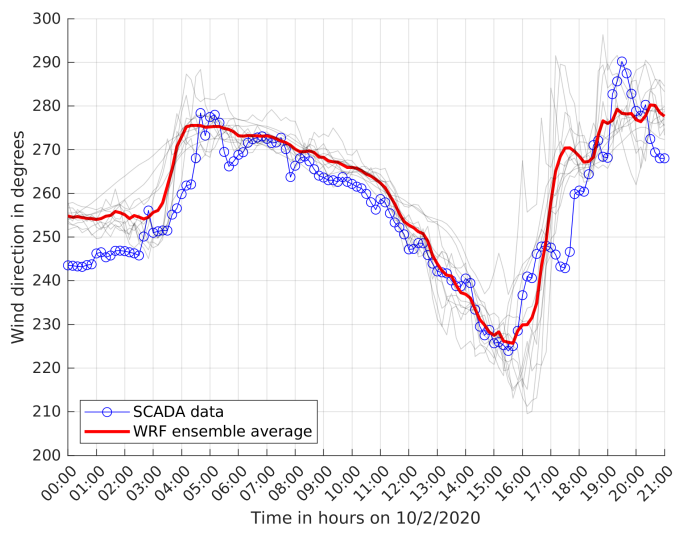

(a)

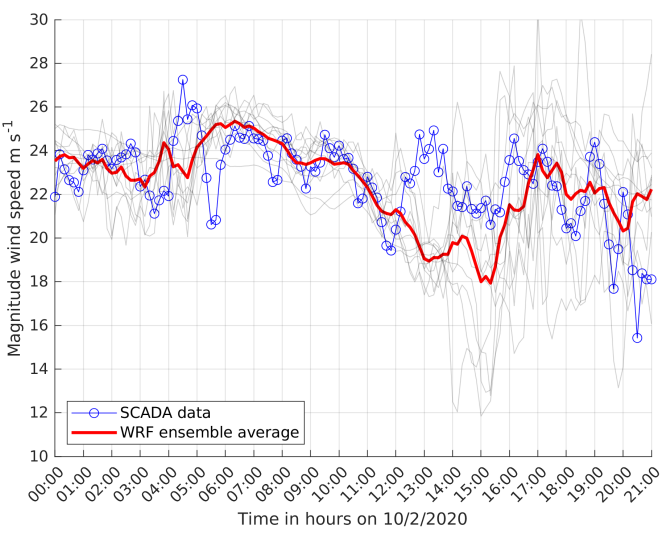

(b)

Figure 3. Ensemble average of WRF on wind direction (a) and wind speed (b) evaluated against SCADA data. Ensemble members shown in gray.

the scale-aware Shin-Hong PBL scheme. Quantitative performance metrics for these simulation pairs are shown in Table 4, whereas a qualitative view is presented in the form of a wind direction time series and a snapshot of RADAR reflectivity in Figs. 5 and 6 respectively.

Focusing firstly on the wind direction, it can be seen in Fig. 5 that the simulations with the larger spatial extent on Domain 2 (yellow lines) produce more short-timescale fluctuations, similar to fluctuations observed in the SCADA data, than those simulations performed on the smaller Domain 1 configuration (orange lines). However, assessing the performance metrics in 


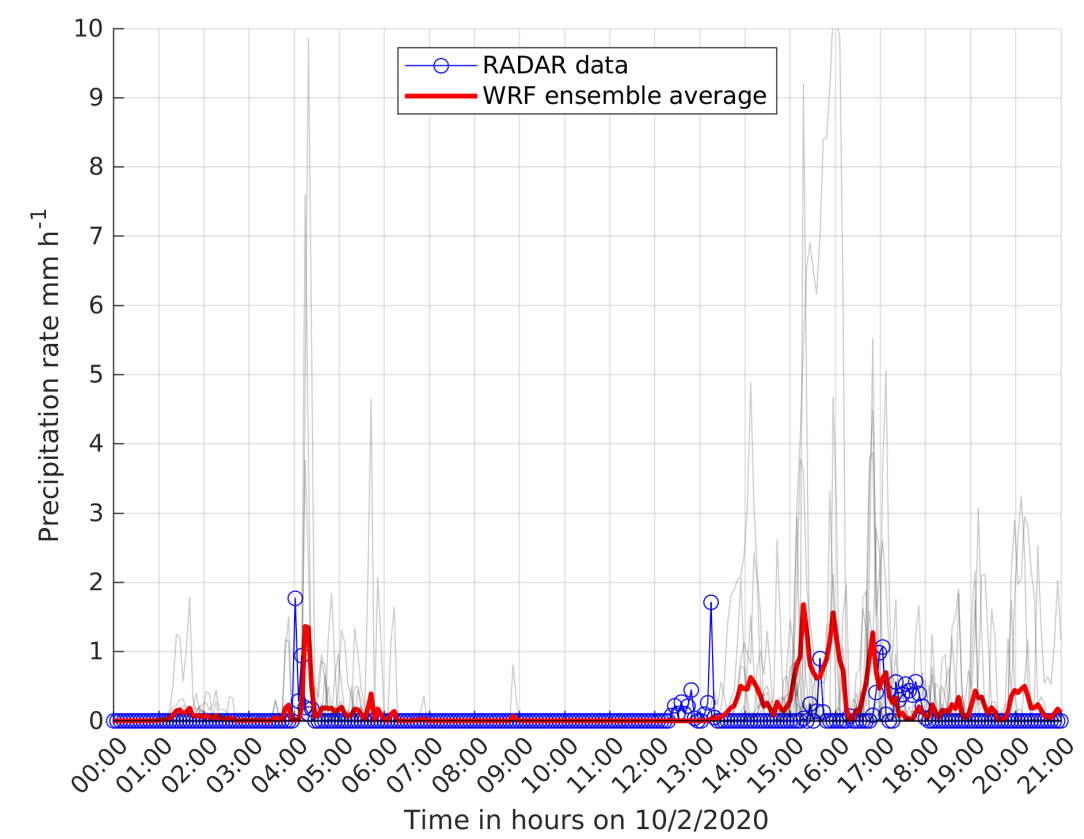

Figure 4. Ensemble average of WRF RADAR reflectivity evaluated against observational RADAR data from RMI-B. Ensemble members shown in gray.

Table 4, this does not immediately translate to a clear reduction in NED for both pair J and K. Even though the Domain 2 fluctuations produce qualitative similarities with the SCADA data, their respective phase differences lead to large errors in MAE, which are only partially corrected for by the improved Kantorovich distance, thus resulting in an inconclusive trend regarding NED. Similar arguments can be made for the wind speed: even though the Domain 2 runs have the potential to provide higher levels of detail, the match with SCADA data does not consistently improve based on our current metrics.

Turning to precipitation, Kantorovich distances from Table 4 clearly indicate simulations on larger Domain 2 to produce better results. Similar findings were also recently observed by Yu et al. (2021). Precipitation levels from WRF-simulated RADAR reflectivity versus observed RADAR reflectivity at 04:40 for simulation pair $\mathrm{K}$ are presented in Fig. 6 . It is shown that whereas the Domain 2 WRF run indicates the presence of bow echo similar to the observed RADAR, little to no RADAR reflectivity is observed for simulations on Domain 1. For simulation pair $\mathbf{J}$ (not further shown here) domain 1 captured significantly less variation in precipitation fronts in comparison to domain 2. Overall, simulations on Domain 2 predicted better convective structures and precipitation cells that are found to be more representative of RADAR observations in comparison to the smaller Domain 1. 
https://doi.org/10.5194/wes-2021-137

Preprint. Discussion started: 21 December 2021

(c) Author(s) 2021. CC BY 4.0 License.

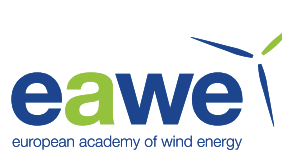

Table 4. Evaluation of simulation pairs $\mathbf{J}$ and $\mathrm{K}$, subject to two different domain configurations using MAE and Kantorovich distance.

\begin{tabular}{|c|c|c|c|c|c|c|c|c|c|c|c|c|c|c|}
\hline \multirow[b]{2}{*}{ \# } & \multirow[b]{2}{*}{$\begin{array}{c}\text { ERA5 } \\
\text { res. }\end{array}$} & \multirow[b]{2}{*}{$\begin{array}{c}\text { Domain } \\
\text { type }\end{array}$} & \multirow[b]{2}{*}{$\begin{array}{c}P B L \\
\text { scheme }\end{array}$} & \multirow[b]{2}{*}{$\begin{array}{c}\text { Microphysics } \\
\text { scheme }\end{array}$} & \multirow[b]{2}{*}{$\begin{array}{c}\text { Cumulus } \\
\text { scheme }\end{array}$} & \multirow[b]{2}{*}{$\begin{array}{c}\text { Domain } \\
\text { pair }\end{array}$} & \multicolumn{3}{|c|}{ Wind direction } & \multicolumn{3}{|c|}{ Wind speed } & \multirow[b]{2}{*}{$\begin{array}{c}\text { Average } \\
\text { NED }\end{array}$} & \multirow{2}{*}{$\begin{array}{l}\text { Precipitation } \\
\text { Kantorovich }\end{array}$} \\
\hline & & & & & & & MAE & Kanto & NED & MAE & Kantorovich & NED & & \\
\hline 4 & $1 \mathrm{~h}$ & 1 & MYNN & Thompson & KF & & 7.61 & $1.05 \mathrm{E}+04$ & 1.55 & 2.72 & $3.47 \mathrm{E}+03$ & 1.70 & 1.63 & $6.57 \mathrm{E}+02$ \\
\hline 3 & $1 \mathrm{~h}$ & 2 & MYNN & Thompson & $\mathrm{KF}$ & & 9.83 & $4.68 \mathrm{E}+03$ & 1.49 & 2.85 & $5.93 \mathrm{E}+03$ & 2.35 & 1.92 & $4.16 \mathrm{E}+02$ \\
\hline 6 & $1 \mathrm{~h}$ & 1 & Shin-Hong & Thompson & $\mathrm{KF}$ & & 5.49 & $1.12 \mathrm{E}+04$ & 1.41 & 2.06 & $3.56 \mathrm{E}+03$ & 1.51 & 1.46 & $5.32 \mathrm{E}+02$ \\
\hline 7 & $1 \mathrm{~h}$ & 2 & Shin-Hong & Thompson & KF & & 6.94 & $1.11 \mathrm{E}+04$ & 1.53 & 2.13 & $3.45 \mathrm{E}+03$ & 1.50 & 1.51 & $3.06 \mathrm{E}+02$ \\
\hline
\end{tabular}

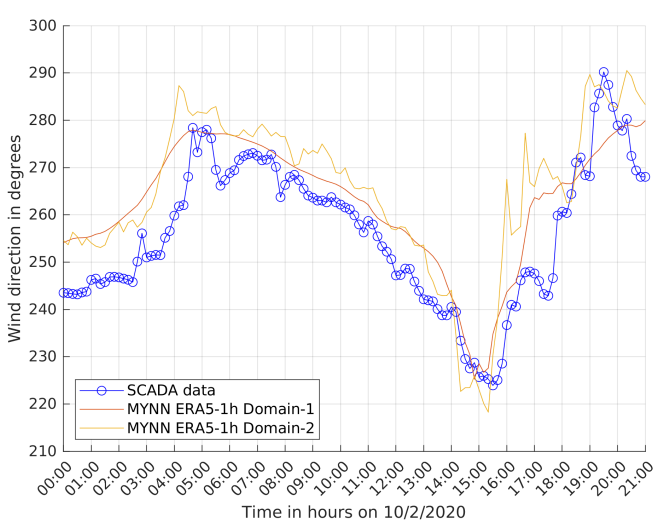

(a)

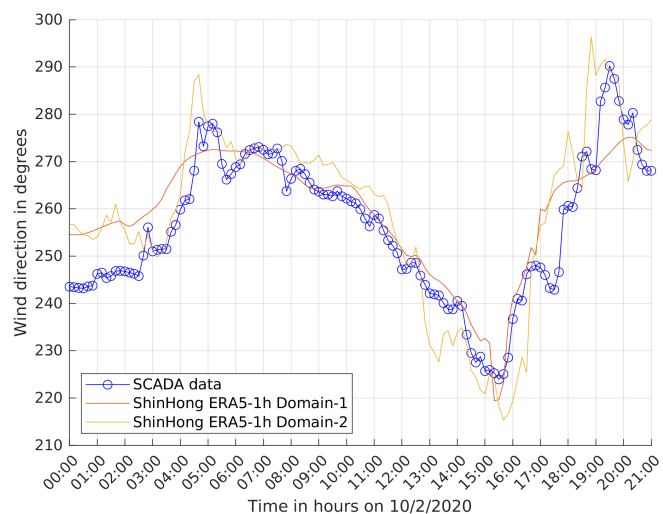

(b)

Figure 5. Wind direction time series at offshore wind farm location from SCADA data and WRF simulations. (a): Simulation pair J. (b): Simulation pair K.
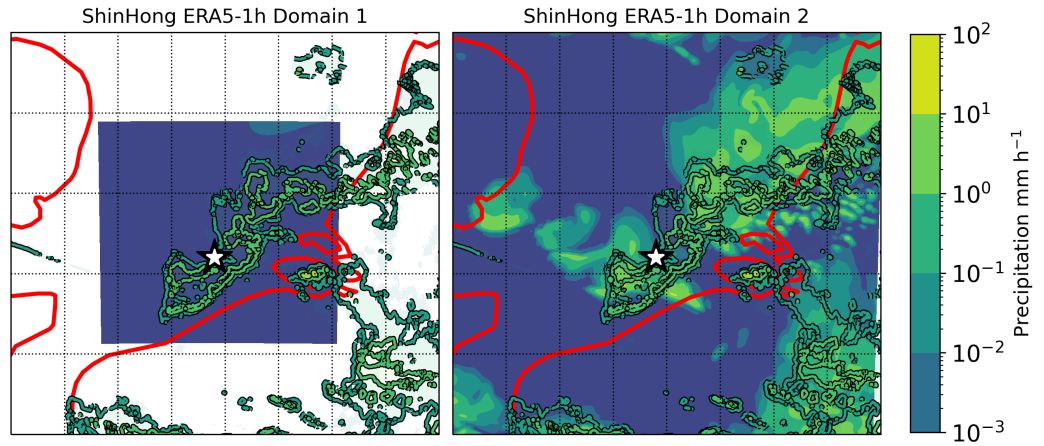

Figure 6. Contours of RADAR precipitation (contour lines in foreground) and WRF precipitation (filled contours in background) for simulation pair K. Left: Simulation on smaller Domain 1. Right: Simulation on larger Domain 2. Color profile are scaled such that similar color patterns represent similar precipitation levels. 
Table 5. Evaluation of simulation pairs H and I, subject to MYNN and Shin-Hong PBL schemes using MAE and Kantorovich distance.

\begin{tabular}{|c|c|c|c|c|c|c|c|c|c|c|c|c|c|c|}
\hline \multirow[b]{2}{*}{$\#$} & \multirow[b]{2}{*}{$\begin{array}{c}\text { ERA5 } \\
\text { res. }\end{array}$} & \multirow[b]{2}{*}{$\begin{array}{c}\text { Domain } \\
\text { type }\end{array}$} & \multirow[b]{2}{*}{$\begin{array}{c}P B L \\
\text { scheme }\end{array}$} & \multirow[b]{2}{*}{$\begin{array}{c}\text { Microphysics } \\
\text { scheme }\end{array}$} & \multirow[b]{2}{*}{$\begin{array}{l}\text { Cumulus } \\
\text { scheme }\end{array}$} & \multirow[b]{2}{*}{$\begin{array}{l}\text { PBL } \\
\text { pair }\end{array}$} & \multicolumn{3}{|c|}{ Wind direction } & \multicolumn{3}{|c|}{ Wind speed } & \multirow[b]{2}{*}{$\begin{array}{c}\text { Average } \\
\text { NED }\end{array}$} & \multirow{2}{*}{$\begin{array}{l}\text { Precipitation } \\
\text { Kantorovich }\end{array}$} \\
\hline & & & & & & & MAE & Kantorovich & NED & MAE & Kantorovich & NED & & \\
\hline 4 & $1 \mathrm{~h}$ & 1 & MYNN & Thompson & KF & \multirow{2}{*}{ H } & 7.61 & $1.05 \mathrm{E}+04$ & 1.55 & 2.72 & $3.47 \mathrm{E}+03$ & 1.70 & 1.63 & $6.57 \mathrm{E}+02$ \\
\hline 6 & $1 \mathrm{~h}$ & 1 & Shin-Hong & Thompson & KF & & 5.49 & $1.12 \mathrm{E}+04$ & 1.41 & 2.06 & $3.56 \mathrm{E}+03$ & 1.51 & 1.46 & $5.32 \mathrm{E}+02$ \\
\hline 3 & $1 \mathrm{~h}$ & 2 & MYNN & Thompson & KF & \multirow{2}{*}{$\mathbf{I}$} & 9.83 & $4.68 \mathrm{E}+03$ & 1.49 & 2.85 & $5.93 E+03$ & 2.35 & 1.92 & $2.97 \mathrm{E}+02$ \\
\hline 7 & $1 \mathrm{~h}$ & 2 & Shin-Hong & Thompson & KF & & 6.94 & $1.11 \mathrm{E}+04$ & 1.53 & 2.13 & $3.45 \mathrm{E}+03$ & 1.50 & 1.51 & $3.06 \mathrm{E}+02$ \\
\hline
\end{tabular}

\subsection{Simulation pair: Planetary boundary layer}

In this section, the influence of using classical non-scale-aware PBL schemes versus using scale-aware PBL schemes is elaborated. More specifically, the standard MYNN scheme is compared to the scale-aware Shin-Hong scheme by simulation pairs $\mathrm{H}$ (run on Domain 1, see previous section) and I (run on Domain 2). Note that these are the same simulations considered in the previous section, but compared in a different manner here. Table 5 contains quantitative performance metrics for these simulation pairs. Furthermore, for simulation pair I, the time series of wind direction and wind speeds are shown in Fig. 7 and a snapshot of RADAR reflectivity is presented in Fig. 8.

Considering wind direction and wind speed first, the simulations with the Shin-Hong PBL scheme observe better concurrence to SCADA data considering MAE. In some cases, the Kantorovich distance however contradicts MAE in favor of the MYNN PBL scheme, resulting in overall similar NED scores for wind direction for Shin-Hong and MYNN. For wind speeds on the other hand, the resulting NED significantly favors scale-aware Shin-Hong. Finally, considering the averaged NED as the defining metric, better overall results were observed for simulations with the scale-aware Shin-Hong PBL scheme.

Even though we observed larger vertical velocity profiles and higher water vapour mixing ratios for Shin-Hong than for MYNN during times of high precipitation (see Fig. 4), the precipitation Kantorovich distance in Table 5 presents inconclusive results regarding which PBL scheme results in a closer match to RADAR data. The qualitative results as presented in Fig. 8 for simulation pair I indicate a better representation of the precipitation front for simulations with the Shin-Hong PBL scheme. However, for simulation pair H (not further shown here), Shin-Hong scheme significantly underestimates the RADAR precipitation.

Overall, current results show the scale-aware Shin-Hong PBL scheme performs generally better for wind variables in the current case, yet results for precipitation could indicate a dependency with cumulus and microphysics parameterizations, which has also been reported in literature (Hong and Dudhia, 2012; Choi and Han, 2020; Chen et al., 2021). 


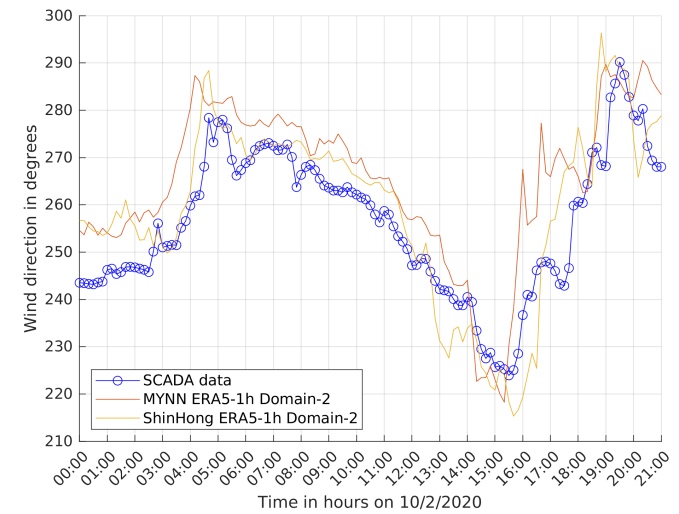

(a)

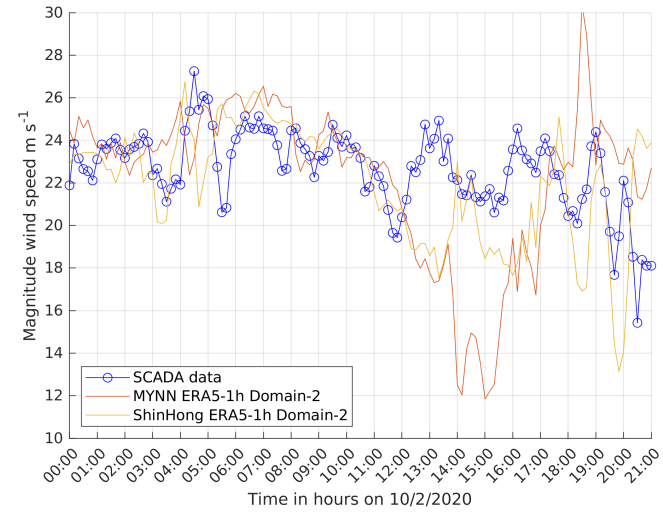

(b)

Figure 7. Time series at offshore wind farm location from SCADA data and WRF simulations for simulation pair I. (a): Wind direction. (b): Wind speed.
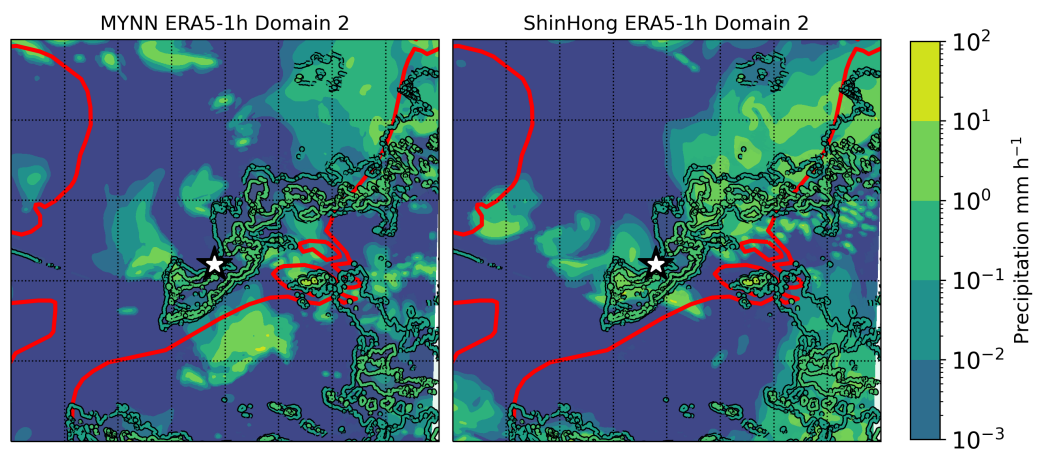

Figure 8. Contours of RADAR precipitation (contour lines in foreground) and WRF precipitation (filled contours in background) for simulation pair I. Left: MYNN PBL scheme. Right: Shin-Hong PBL scheme.

\subsection{Simulation pair: Temporal resolution of lateral boundary conditions}

The effect of varying temporal resolution or update frequency of the ERA5 lateral boundary conditions is investigated in this section. Simulation pairs A and B represent four WRF simulations in which the temporal ERA5 resolution is varied between hourly and three-hourly updates. Note further that A and B mutually differ in all setup parameters other than the cumulus scheme, which justifies them to serve as independent pairs to judge the influence of the temporal boundary condition resolution.

Table 6 consolidates the results for both simulation pairs. The higher hourly temporal resolution for ERA5 lateral boundary conditions produced better results for wind direction, wind speed, and precipitation. Similar results were observed by Hamouda and Pasquero (2021) considering higher resolution of ERA5 dataset to simulate European extreme precipitation. 
Table 6. Evaluation of simulation pairs A and B, subject to $1 \mathrm{~h}$ and $3 \mathrm{~h}$ temporal resolution of lateral boundary conditions using MAE and Kantorovich distance.

\begin{tabular}{|c|c|c|c|c|c|c|c|c|c|c|c|c|c|c|}
\hline \multirow[b]{2}{*}{ \# } & & & & & & & \multicolumn{3}{|c|}{ Wind direction } & \multicolumn{3}{|c|}{ Wind speed } & \multirow[b]{2}{*}{$\begin{array}{c}\text { Average } \\
\text { NED }\end{array}$} & \multirow{2}{*}{$\begin{array}{l}\text { Precipitation } \\
\text { Kantorovich }\end{array}$} \\
\hline & $\begin{array}{c}\text { ERA5 } \\
\text { res. }\end{array}$ & $\begin{array}{c}\text { Domain } \\
\text { type }\end{array}$ & $\begin{array}{c}\text { PBL } \\
\text { scheme }\end{array}$ & $\begin{array}{c}\text { Microphysics } \\
\text { scheme }\end{array}$ & $\begin{array}{l}\text { Cumulus } \\
\text { scheme }\end{array}$ & $\begin{array}{c}\text { Temporal } \\
\text { pair }\end{array}$ & MAE & Kantorovich & NED & MAE & Kantorovich & NED & & \\
\hline 5 & $1 \mathrm{~h}$ & 2 & Shin-Hong & WSM5 & $\mathrm{KF}$ & & 7.50 & $1.24 \mathrm{E}+04$ & 1.69 & 1.76 & $2.57 \mathrm{E}+03$ & 1.17 & 1.43 & $2.97 \mathrm{E}+02$ \\
\hline 1 & $3 \mathrm{~h}$ & 2 & Shin-Hong & WSM5 & KF & & 7.84 & $1.28 \mathrm{E}+04$ & 1.75 & 2.13 & $3.19 \mathrm{E}+03$ & 1.44 & 1.60 & $6.96 \mathrm{E}+02$ \\
\hline 4 & $1 \mathrm{~h}$ & 1 & MYNN & Thompson & $\mathrm{KF}$ & & 7.61 & $1.05 \mathrm{E}+04$ & 1.55 & 2.72 & $3.47 \mathrm{E}+03$ & 1.70 & 1.63 & $6.57 \mathrm{E}+02$ \\
\hline 2 & $3 \mathrm{~h}$ & 1 & MYNN & Thompson & $\mathrm{KF}$ & & 8.79 & $1.06 \mathrm{E}+04$ & 1.67 & 2.96 & $4.11 \mathrm{E}+03$ & 1.93 & 1.80 & $7.42 \mathrm{E}+02$ \\
\hline
\end{tabular}

Figure 9 presents the time-series plots for wind direction for simulation pairs A and B. For both pairs, a slightly better qualitative match with SCADA is shown for the $1 \mathrm{~h}$ resolution runs (orange lines) over the $3 \mathrm{~h}$ runs (yellow lines). Specifically, in pair A, the afternoon through around 15:00 is better captured using the higher temporal resolution, whereas in pair B the peaks at 05:00 and 19:00 are modelled with higher accuracy. Note that the difference in terms of smoothness between pairs A and B can be attributed to the different domain configurations as discussed above in Section 4.1. A qualitative comparison of wind speeds revealed similar trends and is omitted here for brevity.

A qualitative look at the RADAR snapshot in Figure 10 for simulation pair B reveals that whereas the $1 \mathrm{~h}$ resolution run reproduces the main frontal structure of the precipitation, the $3 \mathrm{~h}$ resolution simulation does not show any reflectivity at all. For simulation pair A, which is not further plotted here, no apparent qualitative differences in RADAR reflectivity were observed.

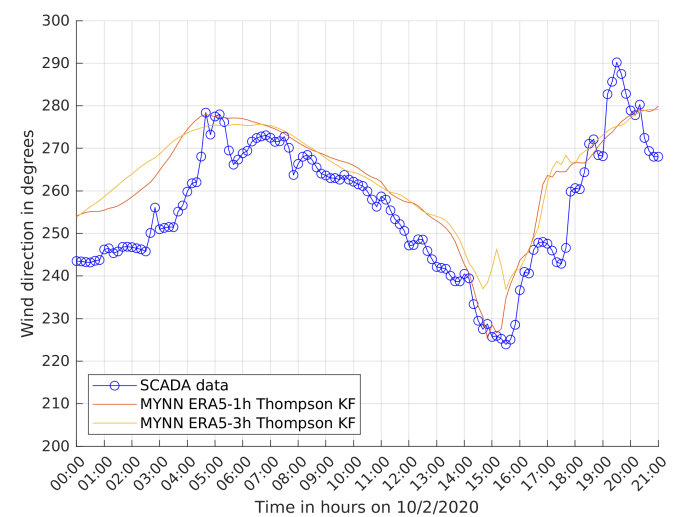

(a)

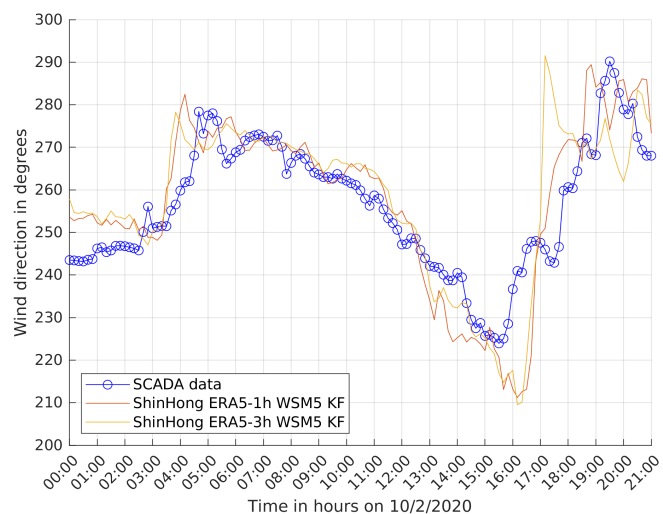

(b)

Figure 9. Time series of wind direction at offshore wind farm location from SCADA data and WRF simulations. (a): Simulation pair B. (b): Simulation pair A 


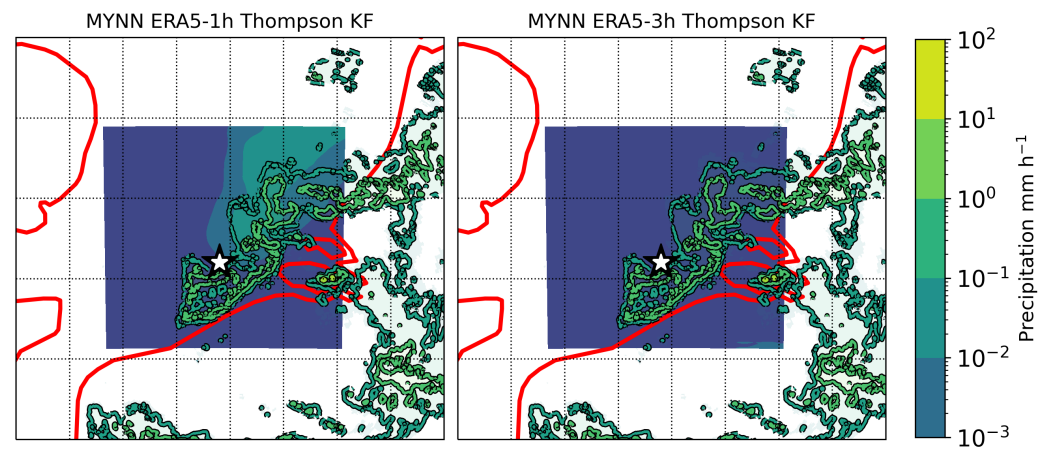

Figure 10. Contours of RADAR precipitation (contour lines in foreground) and WRF precipitation (filled contours in background) for simulation pair B. Left: hourly boundary condition updates. Right: three-hourly boundary condition updates.

\subsection{Simulation pair: Cumulus and Microphysics}

This section presents the consolidated results for cumulus and microphysical scheme variation. Since both of these highlight a specific aspect of modeling precipitation in WRF, they are considered jointly in this section. A set of 7 simulation configurations is considered, covering a combination of 4 cumulus schemes (KF, GD-3D, msKF and GF; the latter two being scale-aware) and 3 microphysical schemes (WSM5, Thompson and Morrison; the latter two representing higher complexity in microphysical parameterization).

Firstly, the wind results for cumulus parameterization pairs are discussed. Pairs C, D and E each allow to assess the influence of the cumulus scheme, while considering one specific microphysics option, i.e. WSM5, Thompson, and Morrison for C, D, and E, respectively. Quantitative results are presented in Table 7. For wind direction and wind speed, scale-aware cumulus parameterizations (msKF and GF) produce better overall NED in comparison to non-scale-aware schemes (KF and GD-3D). The overall outcome, as drawn from average NED, indicate best results for the scale-aware GF cumulus parameterization.

Turning to the wind result sensitivity on microphysical parameterizations in Table 8, simulation pairs F (with KF cumulus) and G (with msKF cumulus) assess the impact of WSM5, Thompson and Morrison schemes. As shown in the table, these simulation pairs do not allow formulating a conclusive trend regarding the impact of microphysics on wind modeling in terms of average NED. However, considering both Table 7 and 8, an observation is that the impact of cumulus schemes on average NED is greater than that of microphysics, and that the best overall performance is obtained using scale-aware cumulus schemes (msKF and GF) combined with high-complexity microphysics (Morrison and Thompson).

For precipitation, results are found to be highly sensitive to the combination of cumulus and microphysics setup. Varying magnitudes and time lags in the precipitation time series were produced by different combinations of cumulus and microphysics schemes, with higher magnitude observed for Morrison and Thompson microphysics coupled with scale-aware cumulus schemes. Qualitatively, the contour plots for WRF versus RADAR observations presented in Fig. 11 also result in significantly different reproductions of precipitation fronts. Once more, both quantitative and qualitative results on precipitation accuracy are inconclusive. 
Table 7. Evaluation of simulation pairs C, D and E, subject to cumulus parameterization sensitivity using MAE and Kantorovich distance.

\begin{tabular}{|c|c|c|c|c|c|c|c|c|c|c|c|c|c|c|}
\hline \multirow[b]{2}{*}{$\#$} & \multirow[b]{2}{*}{$\begin{array}{c}\text { ERA5 } \\
\text { res. }\end{array}$} & \multirow[b]{2}{*}{$\begin{array}{c}\text { Domain } \\
\text { type }\end{array}$} & \multirow[b]{2}{*}{$\begin{array}{c}P B L \\
\text { scheme }\end{array}$} & \multirow[b]{2}{*}{$\begin{array}{c}\text { Microphysics } \\
\text { scheme }\end{array}$} & \multirow[b]{2}{*}{$\begin{array}{l}\text { Cumulus } \\
\text { scheme }\end{array}$} & \multirow[b]{2}{*}{$\begin{array}{c}\text { Cumulus } \\
\text { pair }\end{array}$} & \multicolumn{3}{|c|}{ Wind direction } & \multicolumn{3}{|c|}{ Wind speed } & \multirow[b]{2}{*}{$\begin{array}{c}\text { Average } \\
\text { NED }\end{array}$} & \multirow{2}{*}{$\begin{array}{l}\text { Precipitation } \\
\text { Kantorovich }\end{array}$} \\
\hline & & & & & & & MAE & Kantorovich & NED & MAE & Kantorovich & NED & & \\
\hline 5 & $1 \mathrm{~h}$ & 2 & Shin-Hong & WSM5 & $\mathrm{KF}$ & & 7.50 & $1.24 \mathrm{E}+04$ & 1.69 & 1.76 & $2.57 \mathrm{E}+03$ & 1.17 & 1.43 & $2.97 \mathrm{E}+02$ \\
\hline 8 & $1 \mathrm{~h}$ & 2 & Shin-Hong & WSM5 & msKF & & 6.12 & $1.10 \mathrm{E}+04$ & 1.45 & 1.68 & $1.37 \mathrm{E}+03$ & 0.90 & 1.17 & $6.32 \mathrm{E}+02$ \\
\hline 7 & $1 \mathrm{~h}$ & 2 & Shin-Hong & Thompson & KF & & 6.94 & $1.11 \mathrm{E}+04$ & 1.53 & 2.13 & $3.45 \mathrm{E}+03$ & 1.50 & 1.51 & $3.06 \mathrm{E}+02$ \\
\hline 9 & $1 \mathrm{~h}$ & 2 & Shin-Hong & Thompson & $\mathrm{msKF}$ & & 6.85 & $7.37 \mathrm{E}+03$ & 1.25 & 1.74 & $1.67 \mathrm{E}+03$ & 0.98 & 1.112 & $6.01 \mathrm{E}+02$ \\
\hline 10 & $1 \mathrm{~h}$ & 2 & Shin-Hong & Morrison & $\mathrm{msKF}$ & & 6.06 & $7.37 \mathrm{E}+03$ & 1.16 & 1.87 & $1.74 \mathrm{E}+03$ & 1.04 & 1.10 & $9.61 \mathrm{E}+02$ \\
\hline 11 & $1 \mathrm{~h}$ & 2 & Shin-Hong & Morrison & GD-3D & & 5.24 & $9.71 \mathrm{E}+03$ & 1.26 & 2.07 & $2.97 \mathrm{E}+03$ & 1.37 & 1.32 & 4.99E+02 \\
\hline 12 & $1 \mathrm{~h}$ & 2 & Shin-Hong & Morrison & GF & & 5.87 & $5.65 \mathrm{E}+03$ & 1.03 & 1.80 & $2.61 \mathrm{E}+03$ & 1.20 & 1.111 & $6.50 \mathrm{E}+02$ \\
\hline
\end{tabular}

Table 8. Evaluation of simulation pairs F and G, subject to microphysics parameterization sensitivity using MAE and Kantorovich distance.

\begin{tabular}{|c|c|c|c|c|c|c|c|c|c|c|c|c|c|c|}
\hline \multirow[b]{2}{*}{$\#$} & \multirow[b]{2}{*}{$\begin{array}{c}\text { ERA5 } \\
\text { res. }\end{array}$} & \multirow[b]{2}{*}{$\begin{array}{c}\text { Domain } \\
\text { type }\end{array}$} & \multirow[b]{2}{*}{$\begin{array}{c}P B L \\
\text { scheme }\end{array}$} & \multirow[b]{2}{*}{$\begin{array}{c}\text { Microphysics } \\
\text { scheme }\end{array}$} & \multirow[b]{2}{*}{$\begin{array}{l}\text { Cumulus } \\
\text { scheme }\end{array}$} & \multirow[b]{2}{*}{$\begin{array}{c}\text { Microphysics } \\
\text { pair }\end{array}$} & \multicolumn{3}{|c|}{ Wind direction } & \multicolumn{3}{|c|}{ Wind speed } & \multirow[b]{2}{*}{$\begin{array}{l}\text { Average } \\
\text { NED }\end{array}$} & \multirow{2}{*}{$\begin{array}{l}\text { Precipitation } \\
\text { Kantorovich }\end{array}$} \\
\hline & & & & & & & MAE & Kantorovich & NED & MAE & Kantorovich & NED & & \\
\hline 5 & $1 \mathrm{~h}$ & 2 & Shin-Hong & WSM5 & $\mathrm{KF}$ & & 7.50 & $1.24 \mathrm{E}+04$ & 1.69 & 1.76 & $2.57 \mathrm{E}+03$ & 1.17 & 1.43 & $2.97 \mathrm{E}+02$ \\
\hline 7 & $1 \mathrm{~h}$ & 2 & Shin-Hong & Thompson & $\mathrm{KF}$ & & 6.94 & $1.11 \mathrm{E}+04$ & 1.53 & 2.13 & $3.45 \mathrm{E}+03$ & 1.50 & 1.51 & $3.06 \mathrm{E}+02$ \\
\hline 8 & $1 \mathrm{~h}$ & 2 & Shin-Hong & WSM5 & $\mathrm{msKF}$ & \multirow{3}{*}{ G } & 6.12 & $1.10 \mathrm{E}+04$ & 1.45 & 1.68 & $1.37 \mathrm{E}+03$ & 0.90 & 1.17 & $6.32 \mathrm{E}+02$ \\
\hline 9 & $1 \mathrm{~h}$ & 2 & Shin-Hong & Thompson & msKF & & 6.85 & $7.37 \mathrm{E}+03$ & 1.25 & 1.74 & $1.67 \mathrm{E}+03$ & 0.98 & 1.112 & $6.01 \mathrm{E}+02$ \\
\hline 10 & $1 \mathrm{~h}$ & 2 & Shin-Hong & Morrison & msKF & & 6.06 & 7.37E+03 & 1.16 & 1.87 & $1.74 \mathrm{E}+03$ & 1.04 & 1.10 & $9.61 \mathrm{E}+02$ \\
\hline
\end{tabular}
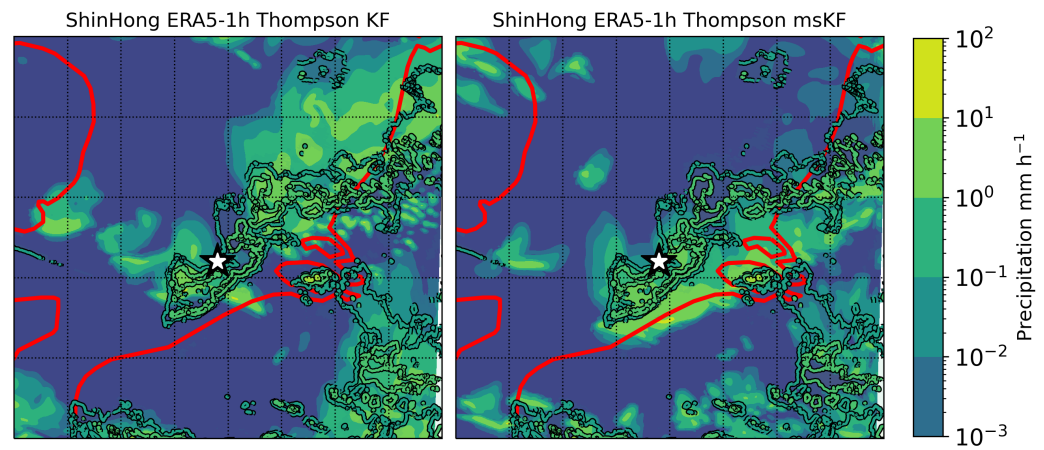

(a) Simulation pair D (Thompson microphysics). Left: KF. Right: multi-scale KF.
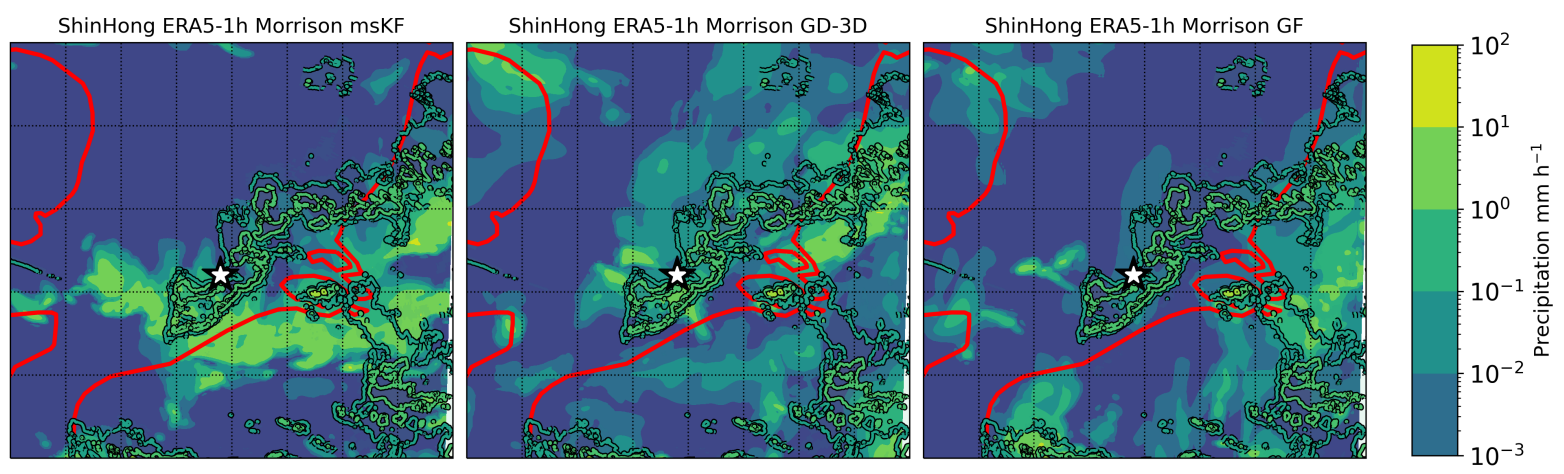

(b) Simulation pair E (Morrison microphysics). Left: multi-scale KF. Center: GD-3D. Right: GF.

Figure 11. Contours of RADAR precipitation (contour lines in foreground) and WRF precipitation (filled contours in background) for (a) simulation pair $\mathrm{D}$ and $(b)$ simulation pair $\mathrm{E}$. 


\subsection{Discussion}

The previous sections investigated the individual influence of varying a single parameterization in the modeling chain on the accuracy of the match between WRF simulation results and field data. Even though a clear trend of increased fidelity with higher model complexity has been observed in Table 3, individual comparisons are more subtle.

When looking at domain configurations, it has been clearly shown that larger computational domains result in significantly more short-timescale fluctuations of wind speed and direction, which closely resemble those present in the field observations. Similar results were observed in a recent study by Yu et al. (2021). Even though this produces qualitatively better time series (see Fig. 5), this does not always translate into an unambiguous improvement of quantitative MAE and Kantorovich metrics considered here (see Table 4). In contrast, for the temporal resolution of the lateral boundary conditions, where the qualitative improvement of higher resolution is somewhat more subtle (see Fig. 9), the quantitative indicators show a unanimous improvement (see Table 6). These observations advocate the use of multiple quantitative and qualitative metrics in sensitivity studies, as well as motivate the development of more advanced metrics to capture the match between simulations and field observations.

For wind speed and direction, a promising trend is observed in which scale-aware PBL and cumulus schemes lead to a better match with SCADA data for the current storm Ciara case. Based on the average NED, simulation case 12 is found to be the most performant for the current storm Ciara case study. Albeit case 12 has the lowest wind direction NED of all considered simulations, it is outperformed by several other setups when focusing on wind speed, and a different evaluation metric might have led to a different simulation ranking. That being said, in terms of wind speed and direction metrics, a clear and significant difference is found between simulations that employ both scale-aware PBL and cumulus schemes (cases $8-12$ ) and those that do not (cases 1 - 7). This justifies the further development and application of scale-aware physics parameterizations.

Results for precipitation are much more inconclusive, i.e. no clear tendency towards higher accuracy with increased model complexity is found. Furthermore, the time series in Fig. 4 and the snapshots in, e.g., Fig. 11 show RADAR reflectivity and associated precipitation produced in different runs to have a very wide spread in reproduction, indicating a strong sensitivity to model setup. Interestingly, the ensemble of all considered simulations ranks second in terms of precipitation accuracy, whereas only fifth in terms of average wind NED metric (see Table 3). These considerations promote the use of ensemble techniques including data assimilation for precipitation modeling.

\section{Conclusions and recommendations}

The complexity in determining the optimal physics setup for the operational use of the WRF-ARW model in wind energy applications has been well established by literature to exhibit strong dependencies on location-specific weather events and the combination of various physics parameterizations. In this study, a multi-variant sensitivity analysis is performed for the extreme weather case of storm Ciara as observed on 10 February 2020 over the Belgian North Sea. The event produced fast changes in wind direction which can potentially lead to significant off-design turbine loading and strong wind-farm power excursions. WRF results for wind direction and wind speed have been evaluated against SCADA data of an operational offshore wind farm. Precipitation results were qualitatively compared to RADAR data from RMI-B. This sensitivity analysis explores the impact 
of temporal resolution of lateral boundary conditions, domain configuration and sub-grid scale modelling techniques used for PBL, cumulus and microphysical parameterizations.

The results of this sensitivity analysis indicate better performance for wind variables when considering scale-aware parameterization techniques. More specifically, a clear distinction was observed between simulations that employ scale-aware schemes for both PBL and cumulus schemes and those that do not. In view of modeling SCADA wind speed and direction, the most performant combination of setup and parameterizations consists of a scale-aware Shin-Hong planetary boundary layer scheme coupled with scale-aware Grell-Freitas cumulus parameterization, 6-class double moment Morrison microphysics, together with hourly boundary condition updates on extended simulation domains. The representation of precipitation fronts on the other hand is shown to be highly sensitive to model setup, and no quantitative trends could be observed. That said, results for the ensemble average of precipitation are promising.

In terms of future work, expanding the current sensitivity analysis to other high-impact weather events is an important topic to assess the generalization of the current observations. Additionally, further study on the sensitivity and adequate modeling of precipitation is necessary, including data assimilation of operational RADAR data in the simulations to improve model initialization, as well as dedicated localized precipitation measurements to provide reliable field data. Finally, an interesting area of further research would be to perform similar sensitivity studies at finer sub-kilometer resolutions including recent advancements such as three-dimensional scale-aware PBL schemes such as in Zhang et al. (2018) and Senel et al. (2020).

Acknowledgements. This work has received funding from the Flemish Government through the Agency for Innovation and Entrepreneurship (Vlaams Agentschap Innoveren en Ondernemen, VLAIO) through the cSBO project SeaFD in the context of the MaDurOS program for Material Durability for Off-Shore of the cluster on Strategic Initiatives for Materials in Flanders (SIM). Furthermore, the authors acknowledge VLAIO funding through the RAINBOW project in the context of SIM and the Blue Cluster. The authors thank dr. Laurent Delobbe from the Royal Meteorological Institute of Belgium for providing RADAR reflectivity data from the dual-polarization C-band RADAR, located in Jabbeke at the Belgian North Sea coast. 


\section{References}

AbuGazia, M., El Damatty, A. A., Dai, K., Lu, W., and Ibrahim, A.: Numerical model for analysis of wind turbines under tornadoes, Engineering Structures, 223, 111 157, 2020.

Aird, J. A., Barthelmie, R. J., Shepherd, T. J., and Pryor, S. C.: WRF-simulated low-level jets over Iowa: characterization and sensitivity studies, Wind Energy Science, 6, 1015-1030, 2021.

Arakawa, A., Jung, J.-H., and Wu, C.-M.: Toward unification of the multiscale modeling of the atmosphere, Atmospheric Chemistry and Physics, 11, 3731-3742, 2011.

Bakhshi, R. and Sandborn, P.: The effect of yaw error on the reliability of wind turbine blades, in: Energy Sustainability, vol. 50220, p. V001T14A001, American Society of Mechanical Engineers, 2016.

Bauer, P., Thorpe, A., and Brunet, G.: The quiet revolution of numerical weather prediction, Nature, 525, 47-55, 2015.

Bhaskaran, B., Jones, R., Murphy, J., and Noguer, M.: Simulations of the Indian summer monsoon using a nested regional climate model: domain size experiments, Climate Dynamics, 12, 573-587, 1996.

Carvalho, D., Rocha, A., Gómez-Gesteira, M., and Santos, C.: A sensitivity study of the WRF model in wind simulation for an area of high wind energy, Environmental Modelling \& Software, 33, 23-34, 2012.

Carvalho, D., Rocha, A., Gómez-Gesteira, M., and Santos, C. S.: Sensitivity of the WRF model wind simulation and wind energy production estimates to planetary boundary layer parameterizations for onshore and offshore areas in the Iberian Peninsula, Applied Energy, 135, 234-246, 2014.

Chen, X., Xue, M., Zhou, B., Fang, J., Zhang, J. A., and Marks, F. D.: Effect of Scale-Aware Planetary Boundary Layer Schemes on Tropical Cyclone Intensification and Structural Changes in the Gray Zone, Monthly Weather Review, 149, 2079-2095, 2021.

Chi, S.-Y., Liu, C.-J., Tan, C.-H., and Chen, Y.-H.: Study of typhoon impacts on the foundation design of offshore wind turbines in Taiwan, Proceedings of the Institution of Civil Engineers-Forensic Engineering, 173, 35-47, 2020.

Choi, H.-J. and Han, J.-Y.: Effect of scale-aware nonlocal planetary boundary layer scheme on lake-effect precipitation at gray-zone resolutions, Monthly Weather Review, 148, 2761-2776, 2020.

Cunden, T. M., Dhunny, A., Lollchund, M., and Rughooputh, S.: Sensitivity Analysis of WRF Model for Wind Modelling Over a Complex Topography under Extreme Weather Conditions, in: 2018 5th International Symposium on Environment-Friendly Energies and Applications (EFEA), pp. 1-6, IEEE, 2018.

Damiani, R., Dana, S., Annoni, J., Fleming, P., Roadman, J., van Dam, J., and Dykes, K.: Assessment of wind turbine component loads under yaw-offset conditions, Wind Energy Science, 3, 173-189, 2018.

Doubrawa, P. and Muñoz-Esparza, D.: Simulating real atmospheric boundary layers at gray-zone resolutions: How do currently available turbulence parameterizations perform?, Atmosphere, 11, 345, 2020.

Efstathiou, G., Zoumakis, N., Melas, D., Lolis, C., and Kassomenos, P.: Sensitivity of WRF to boundary layer parameterizations in simulating a heavy rainfall event using different microphysical schemes. Effect on large-scale processes, Atmospheric Research, 132-133, 125-143, https://doi.org/https://doi.org/10.1016/j.atmosres.2013.05.004, 2013.

Fujita, T. T.: Manual of downburst identification for project NIMROD., SMRP Res. Paper, 156, 104, 1978.

Gallego-Castillo, C., Cuerva-Tejero, A., and Lopez-Garcia, O.: A review on the recent history of wind power ramp forecasting, Renewable and Sustainable Energy Reviews, 52, 1148-1157, 2015. 
https://doi.org/10.5194/wes-2021-137

Preprint. Discussion started: 21 December 2021

(c) Author(s) 2021. CC BY 4.0 License.

(c) (i)

García-Díez, M., Fernández, J., Fita, L., and Yagüe, C.: Seasonal dependence of WRF model biases and sensitivity to PBL schemes over

Europe, QJ Roy. Meteor. Soc., 139, 501-514, 2013.

Giannakopoulou, E.-M. and Nhili, R.: WRF model methodology for offshore wind energy applications, Advances in Meteorology, 2014, 2014.

Grell, G. A. and Dévényi, D.: A generalized approach to parameterizing convection combining ensemble and data assimilation techniques, Geophysical Research Letters, 29, 38-1, 2002.

400 Grell, G. A. and Freitas, S. R.: A scale and aerosol aware stochastic convective parameterization for weather and air quality modeling, Atmospheric Chemistry and Physics, 14, 5233-5250, 2014.

Hahmann, A. N., Vincent, C. L., Peña, A., Lange, J., and Hasager, C. B.: Wind climate estimation using WRF model output: method and model sensitivities over the sea, International Journal of Climatology, 35, 3422-3439, 2015.

Hamouda, M. E. and Pasquero, C.: European extreme precipitation: The effects of spatio-temporal resolution of the data, Weather and Climate Extremes, p. 100337, 2021.

Hong, S.-Y. and Dudhia, J.: Next-generation numerical weather prediction: Bridging parameterization, explicit clouds, and large eddies, Bulletin of the American Meteorological Society, 93, ES6-ES9, 2012.

Hong, S.-Y. and Lim, J.-O. J.: The WRF single-moment 6-class microphysics scheme (WSM6), Asia-Pacific Journal of Atmospheric Sciences, 42, 129-151, 2006.

410 Hong, S.-Y., Dudhia, J., and Chen, S.-H.: A revised approach to ice microphysical processes for the bulk parameterization of clouds and precipitation, Monthly weather review, 132, 103-120, 2004.

Hong, S.-Y., Noh, Y., and Dudhia, J.: A new vertical diffusion package with an explicit treatment of entrainment processes, Monthly weather review, 134, 2318-2341, 2006.

Huang, H., Winter, J. M., Osterberg, E. C., Hanrahan, J., Bruyère, C. L., Clemins, P., and Beckage, B.: Simulating precipitation and temperature in the Lake Champlain basin using a regional climate model: limitations and uncertainties, Climate Dynamics, 54, 69-84, 2020.

Iacono, M. J., Delamere, J. S., Mlawer, E. J., Shephard, M. W., Clough, S. A., and Collins, W. D.: Radiative forcing by long-lived greenhouse gases: Calculations with the AER radiative transfer models, Journal of Geophysical Research: Atmospheres, $113,2008$.

Islam, T., Srivastava, P. K., Rico-Ramirez, M. A., Dai, Q., Gupta, M., and Singh, S. K.: Tracking a tropical cyclone through WRF-ARW simulation and sensitivity of model physics, Natural Hazards, 76, 1473-1495, 2015.

420 Jeworrek, J., West, G., and Stull, R.: Evaluation of cumulus and microphysics parameterizations in WRF across the convective gray zone, Weather and Forecasting, 34, 1097-1115, 2019.

Kain, J. S.: The Kain-Fritsch convective parameterization: an update, Journal of applied meteorology, 43, 170-181, 2004.

Kala, J., Andrys, J., Lyons, T. J., Foster, I. J., and Evans, B. J.: Sensitivity of WRF to driving data and physics options on a seasonal time-scale for the southwest of Western Australia, Climate Dynamics, 44, 633-659, 2015.

Kalverla, P. C., Steeneveld, G.-J., Ronda, R. J., and Holtslag, A. A.: An observational climatology of anomalous wind events at offshore meteomast IJmuiden (North Sea), Journal of Wind Engineering and Industrial Aerodynamics, 165, 86-99, 2017.

Kantorovitch, L.: On the translocation of masses, Management science, 5, 1-4, 1958.

Law, H. and Koutsos, V.: Leading edge erosion of wind turbines: Effect of solid airborne particles and rain on operational wind farms, Wind Energy, 23, 1955-1965, https://doi.org/https://doi.org/10.1002/we.2540, 2020.

430 Marshall, J. and Palmer, W.: Relation of raindrop size to intensity, Journal of Meteorology, 5, 165-166, 1948. 
https://doi.org/10.5194/wes-2021-137

Preprint. Discussion started: 21 December 2021

(c) Author(s) 2021. CC BY 4.0 License.

(c) (i)

Mooney, P., Mulligan, F., and Fealy, R.: Evaluation of the sensitivity of the weather research and forecasting model to parameterization schemes for regional climates of Europe over the period 1990-95, Journal of Climate, 26, 1002-1017, 2013.

Morrison, H., Thompson, G., and Tatarskii, V.: Impact of cloud microphysics on the development of trailing stratiform precipitation in a simulated squall line: Comparison of one-and two-moment schemes, Monthly weather review, 137, 991-1007, 2009.

Mukul Tewari, N., Tewari, M., Chen, F., Wang, W., Dudhia, J., LeMone, M., Mitchell, K., Ek, M., Gayno, G., Wegiel, J., et al.: Implementation and verification of the unified NOAH land surface model in the WRF model (Formerly Paper Number 17.5), in: 20th conference on weather analysis and forecasting/16th conference on numerical weather prediction, pp. 11-15, 2004.

Nakanishi, M. and Niino, H.: An improved Mellor-Yamada level-3 model: Its numerical stability and application to a regional prediction of advection fog, Boundary-Layer Meteorology, 119, 397-407, 2006.

Negro, V., López-Gutiérrez, J.-S., Esteban, M. D., and Matutano, C.: Uncertainties in the design of support structures and foundations for offshore wind turbines, Renewable energy, 63, 125-132, 2014.

Santos-Alamillos, F., Pozo-Vázquez, D., Ruiz-Arias, J., Lara-Fanego, V., and Tovar-Pescador, J.: Analysis of WRF model wind estimate sensitivity to physics parameterization choice and terrain representation in Andalusia (Southern Spain), Journal of Applied Meteorology and Climatology, 52, 1592-1609, 2013.

Senel, C. B., Temel, O., Muñoz-Esparza, D., Parente, A., and van Beeck, J.: Gray zone partitioning functions and parameterization of turbulence fluxes in the convective atmospheric boundary layer, Journal of Geophysical Research: Atmospheres, 125, e2020JD033 581, 2020.

Shin, H. H. and Hong, S.-Y.: Representation of the subgrid-scale turbulent transport in convective boundary layers at gray-zone resolutions, Monthly Weather Review, 143, 250-271, 2015.

Skamarock, W. C., Klemp, J., Dudhia, J., Gill, D., Barker, D., Duda, M., Huang, X., Wang, W., and Powers, J.: A description of the Advanced Research (WRF) model, Version 3, Natl. Ctr. Atmos. Res., Boulder, CO, 7, 2008.

Solari, G.: Thunderstorm Downbursts and Wind Loading of Structures: Progress and Prospect. Front, Built Environ, 6, 63, 2020.

Stergiou, I., Tagaris, E., and Sotiropoulou, R.-E. P.: Sensitivity assessment of WRF parameterizations over Europe, in: Multidisciplinary digital publishing institute proceedings, vol. 1, p. 119, 2017.

Thompson, G., Field, P. R., Rasmussen, R. M., and Hall, W. D.: Explicit forecasts of winter precipitation using an improved bulk microphysics scheme. Part II: Implementation of a new snow parameterization, Monthly Weather Review, 136, 5095-5115, 2008.

Wang, X., Zhao, C., Xu, M., Du, Q., Zheng, J., and Bi, Y.: Robustness of simulating aerosol climatic impacts using regional model (WRFChem v3. 6): the sensitivity to domain size, Geoscientific Model Development Discussions, pp. 1-46, 2021.

Wang, Y. and Basu, S.: Utilizing the Kantorovich metric for the validation of optical turbulence predictions, Optics letters, 41, 4008-4011, 2016.

Wyngaard, J. C.: Toward numerical modeling in the "Terra Incognita”, Journal of Atmospheric Sciences, 61, 1816-1826, 2004.

$\mathrm{Xu}, \mathrm{H}$., Wang, Y., and Wang, M.: The performance of a scale-aware nonlocal PBL scheme for the subkilometer simulation of a deep CBL over the Taklimakan Desert, Adv. Meteor., 8759594, 2018.

Yu, Z., Wu, M., Min, J., Yan, Y., and Lou, X.: Impacts of WRF Model Domain Size on Meiyu Rainfall Forecasts over Zhejiang, China, Asia-Pacific Journal of Atmospheric Sciences, pp. 1-16, 2021.

Zhang, X., Bao, J.-W., Chen, B., and Grell, E. D.: A three-dimensional scale-adaptive turbulent kinetic energy scheme in the WRF-ARW model, Monthly Weather Review, 146, 2023-2045, 2018. 
https://doi.org/10.5194/wes-2021-137

Preprint. Discussion started: 21 December 2021

(C) Author(s) 2021. CC BY 4.0 License.

(c) (i)

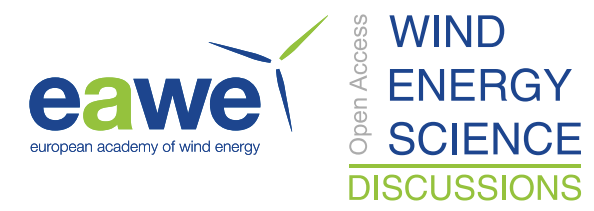

Zheng, Y., Alapaty, K., Herwehe, J. A., Del Genio, A. D., and Niyogi, D.: Improving high-resolution weather forecasts using the Weather Research and Forecasting (WRF) Model with an updated Kain-Fritsch scheme, Monthly Weather Review, 144, 833-860, 2016. 